\title{
Growth and differentiation factor-9 promotes adhesive and motile capacity of prostate cancer cells by up-regulating FAK and Paxillin via Smad dependent pathway
}

\author{
SIVAN M. BOKOBZA, LIN YE, HOWARD G. KYNASTON and WEN G. JIANG \\ Department of Surgery, Metastasis and Angiogenesis Research Group, Cardiff University \\ School of Medicine, Heath Park, Cardiff, CF14 4XN, UK
}

Received June 23, 2010; Accepted July 26, 2010

DOI: 10.3892/or_00001030

\begin{abstract}
The majority of advanced prostate cancers metastasise to the bone. Mediators of bone remodelling, the bone morphogenetic proteins have extensively been implicated in the progression and metastasis of prostate cancer. The present study investigated the function of BMP member GDF-9, in prostate cancer. We overexpressed GDF9 in PC-3 cells using a mammalian expression construct, and knocked-down with the use of ribozyme transgenes. These cells were further used in in vitro adhesion and motility assays, in order to determine the effect of GDF-9 on these properties. Recombinant GDF-9 was generated to treat PC-3 WT cells before further analysing the effect on adhesion. The GDF-9 overexpressing PC-3 cells demonstrated a significantly enhanced adhesive and motile capacity compared to their controls. The opposite effect was seen in the GDF-9 knock-down cells. In addition, treating PC-3 cells with rh-GDF-9 resulted in them becoming more adhesive. Both endogenous and exogenous GDF-9 was demonstrated to up-regulate focal adhesion associated proteins FAK and paxillin which contribute to promoted cell adhesion and motility. With the use of a Smad3 inhibitor, this effect was inhibited suggesting that GDF-9 signals via Smad3 to upregulate expression of these proteins. This study shows that GDF-9 can promote the motile and adhesive capacity of PC-3 prostate cancer cells by up-regulating expression of FAK and paxillin in a Smad dependent manner, suggesting a pro-tumourigenic role for GDF-9 in prostate cancer.
\end{abstract}

\section{Introduction}

Prostate cancer is the leading cancer in men of the developed world, and is only behind lung cancer in terms of most deaths

Correspondence to: Sivan M. Bokobza, Department of Surgery, Metastasis and Angiogenesis Research Group, Cardiff University School of Medicine, Heath Park, Cardiff, CF14 4XN, UK

E-mail: bokobzasm@cf.ac.uk

Key words: bone morphogenetic protein, GDF-9, prostate cancer, motility, FAK associated with cancer (1). Metastatic prostate cancer is accountable for the bulk of deaths associated with the disease, and as of yet no curable treatment has been discovered. For this reason the phenomenon of metastasis has become an intensively studied area, and it is anticipated that a more thorough understanding of the mechanisms behind the process will give rise to novel therapeutic targets, capable of delaying or preventing prostate cancer from metastasising.

Advanced prostate cancers most commonly metastasise to the bone, where these metastases are commonly associated with bone pain and pathological fractures. In the bone microenvironment, bone cells are regulated by a range of different growth factors, including the bone morphogenetic proteins (BMPs) (2). These growth factors belong to a huge family of proteins known as the transforming growth factor- $\beta$ (TGF- $\beta$ ) super family, a group of pleiotropic growth-factors vital in the process of embryonic development where they regulate a large variety of important processes including; proliferation, apoptosis, differentiation, and invasion in an assortment of cell types (3). Unsurprisingly then, many BMPs have been recently shown to be involved in the progression of prostate cancer.

In the prostate, TGF- $\beta$ plays a critical role in controlling androgen dependence, and has been shown to induce loss of sensitivity to hormone mediated growth inhibition, and hence has been implicated in prostate cancer progression. BMPs initiate their downstream signalling via two types of specific receptors (BMPRs), known as type I and II serine/threonine kinase receptors (4). When a BMP ligand binds to its receptors it is capable of triggering either the Smad dependent via Smads 1, 5 and 8, or Smads 2 and 3, or the Smad-independent pathway via MAPK signalling (5).

The role of BMP signalling in prostate cancer has been thoroughly researched and elucidated. In the normal prostate for example, expression of BMP-2 and -4 is predominant, but considerable amounts of BMP-5, -6 and -7 are also present. When comparing to prostate cancer tissues, expression of BMP-2 and -4 is slightly reduced, but BMP-7 expression is significantly lower than in normal prostate sample (6). Additionally, we have recently shown that expression of BMP-9 and -10 is decreased or absent in prostate cancer tissues, especially in those of a higher grade (7).

Due to the clear importance of BMPs in prostate cancer, this study investigated the effects of a relatively unstudied 
Table I. PCR primer sequences.

\begin{tabular}{|c|c|c|c|c|}
\hline Gene & Primer name & Primer sequence $\left(5^{\prime}-3^{\prime}\right)$ & $\begin{array}{l}\text { Annealing } \\
\text { temperature }\left({ }^{\circ} \mathrm{C}\right)\end{array}$ & $\begin{array}{l}\text { Product } \\
\text { size (bps) }\end{array}$ \\
\hline GDF9a & $\begin{array}{l}\text { GDF9aExF1 } \\
\text { GDF9aExR1 } \\
\text { GDF9aExR2 }\end{array}$ & $\begin{array}{l}\text { ATGGCACGTCCCAACAAAT } \\
\text { ATTTGACAGCAGAGGAAAAA } \\
\text { TTAACGACAGGTGCACTTTGTAGC }\end{array}$ & $60-65$ & 1362 \\
\hline $\begin{array}{l}\text { GDF9a } \\
\text { ribozyme-2 }\end{array}$ & $\begin{array}{l}\text { GDF9aRIB2F } \\
\text { GDF9aRIB2R }\end{array}$ & $\begin{array}{l}\text { CTGCAGTAAGTGTTCAACGGTAGTAATGCCTGATGAGT } \\
\text { CCGTGAGG } \\
\text { ACTAGTGGAACTGCTATTTAACCTGGATTTCGTCCTCA } \\
\text { CGGACT }\end{array}$ & 60 & 99 \\
\hline $\begin{array}{l}\text { GDF9a } \\
\text { ribozyme-3 }\end{array}$ & $\begin{array}{l}\text { GDF9aRIB3F } \\
\text { GDF9aRIB3R }\end{array}$ & $\begin{array}{l}\text { CTGCAGCTGTGATAAGCCTGAGCACTTGTGTCATTCAA } \\
\text { ATATAACTGATGAGTCCGTGAGGA } \\
\text { ACTAGTTTTAACATGACTCTGGTGTCCCCCTCACTGAT } \\
\text { TTCGTCCTCACGGACT }\end{array}$ & 62 & 102 \\
\hline GDF9 & $\begin{array}{l}\text { GDF9F9 } \\
\text { GDF9R9 }\end{array}$ & $\begin{array}{l}\text { GCGCTTTTCAAAGTTCTATC } \\
\text { GGTCACATCAATCTGAATCC }\end{array}$ & 56 & 432 \\
\hline FAK & $\begin{array}{l}\text { FAKF1 } \\
\text { FAKzR }\end{array}$ & $\begin{array}{l}\text { AACAGGTGAAGAGCGATTAT } \\
\text { ACTGAACCTGACCGTACACAGTATGATCGCCGTATTTC }\end{array}$ & 56 & 99 \\
\hline Paxillin & $\begin{array}{l}\text { PaxF1 } \\
\text { PaxzR }\end{array}$ & $\begin{array}{l}\text { CAATCCTTGACCCCTTAGA } \\
\text { ACTGAACCTGACCGTACATTGGAGACACTGGAAGTTTT }\end{array}$ & 56 & 115 \\
\hline$ß$-actin & $\begin{array}{l}\text { BactF } \\
\text { BactR }\end{array}$ & $\begin{array}{l}\text { ATGATATCGCCGCGCTCG } \\
\text { CGCTCGGTGAGGATCTTCA }\end{array}$ & 55 & 580 \\
\hline
\end{tabular}

member of the BMP family on prostate cancer cells. GDF-9 is an established oocyte growth factor vital during the early stages of folliculogenesis and ovulation (8). Only recently has its role in cancer been investigated. Despite this however, GDF-9 still lacks a clear role in human cancer progression. This study therefore aimed to determine the effects that GDF9 has on prostate cancer progression, and more specifically prostate cancer cell biological properties.

\section{Materials and methods}

Materials. Mouse monoclonal anti-FAK and anti-paxillin were obtained from BD transduction Laboratories, polyclonal goat anti-GDF-9 antibody and rabbit anti-p-FAK, anti-ppaxillin and anti-pSMAD3 antibodies were obtained from Santa Cruz Biotechnology (Santa Cruz, CA, USA). The primers used are shown in Table I and were synthesised and provided by Sigma-Genesis (Poole, UK).

Cell lines. The cell lines used in this study include PC-3 which was acquired from the European Collection of Animal Cell Culture (ECACC, Salisbury, UK). The cells were routinely maintained in DMEM-F12 medium supplemented with $10 \%$ foetal calf serum and antibiotics.

Generation of GDF-9 ribozyme transgenes. The expression of GDF-9 in PC-3 cells was knocked-down with the use of anti-human GDF-9 hammerhead ribozyme transgenes, designed by being based on the secondary structure of GDF-9 mRNA using Zuker's RNA mFold program (7). These ribozymes were cloned into pEF6/His TOPO mammalian expression plasmid vectors (Invitrogen Inc., Paisley, UK). Control empty plasmid vectors and the ribozyme transgene plasmids were then transfected into PC-3 cells which underwent selection with $5 \mu \mathrm{g} / \mathrm{ml}$ blasticidin for $\sim 2$ weeks before further use.

Overexpression of GDF-9 in PC-3 cells. The GDF-9 coding sequence was amplified using high fidelity PCR (LA-PCR) with the DuraScript ${ }^{\mathrm{TM}}$ RT-PCR kit (Sigma-Aldrich, Inc., Poole, Dorset, UK), and was then cloned into pEF6/V5/His vectors which was transfected into PC-3 cells. After selection with blasticidin the cells were used for the present study.

Generation of recombinant GDF-9. 3T3 cells were transfected with a GDF-9 plasmid containing a histidine tag to help with protein purification. The HiTrap ${ }^{\mathrm{TM}}$ purification kit (Amersham Bioscience UK Ltd., Buckinghamshire, UK) was then used to purify Recombinant GDF-9 (rh-GDF-9) via metal (nickel) chelating affinity chromatography.

RNA isolation, $c D N A$ synthesis and RT-PCR. RNA was isolated using the ABgene Total RNA Isolation Reagent (TRIR) kit (ABgene, Surrey, UK). RT-PCR was then performed using standard methods. 
SDS-PAGE and Western blot analysis. Protein samples were separated on a $10 \%$ polyacrylamide gel, and following SDSPAGE, were transferred onto nitrocellulose membranes. These membranes were blocked and probed with the specific primary (1:250) and corresponding peroxidise-conjugated secondary antibodies $(1: 1000)$ for $1 \mathrm{~h}$, respectively. The resulting bands were finally visualised using the Supersignal ${ }^{\mathrm{TM}}$ West Dura system (Pierce Biotechnology, USA).

Immuno-fluorescent staining of pSmad3. The cells were blocked, and probed with anti-pSmad3 primary antibody followed by corresponding FITC-labelled secondary antibody at a concentration of 1:100. The staining was visualised using the Olympus BX51 fluorescent microscope.

In vitro cell-matrix adhesion assay. The procedure was carried out as previously described (9). Cells (40000) were seeded into a 96 -well plate pre-coated with $5 \mu \mathrm{g} / \mathrm{ml}$ of Matrigel $^{\mathrm{TM}}$. The cells were left to adhere to the Matrigel for a period of $40 \mathrm{~min}$, following which the adherent cells stained with crystal violet and counted.

In vitro cytodex-2 bead motility assay. The procedure was carried out as previously described (9). The cells were incubated with cytodex -2 beads and left over night, by which time the cells had adhered to the surface of the beads. The beads carrying the cells were then transferred into a 24-well plate, where the cells move from the beads onto the surface of the culture plate. These cells were then stained with crystal violet and counted.

Stastical analysis. Statistical analysis was carried out using Minitab $^{\circledR}$ version 14. The Mann-whitney test was used for non-normally distributed data and the two sample T test was used for normally distributed data.

\section{Results}

Effect of GDF-9 on prostate cancer cell adhesion. GDF-9 overexpression and knock-down was confirmed in PC-3 cells at both the mRNA and protein level using RT-PCR and

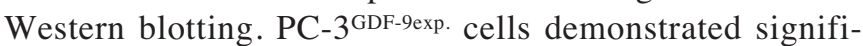
cantly higher expression levels of GDF-9 compared to PC-3 3 WT and $\mathrm{PC}-3^{\mathrm{pEF}}$, whereas $\mathrm{PC}-3^{\mathrm{GDF}-9 \mathrm{rib}} \mathrm{demonstrated}$ reduced levels (Fig. 1A and B).

The cells were further analysed for their adhesive capacity in an in vitro adhesion assay, where a significantly larger number of PC-3 $3^{\text {GDF-9exp. cells }(70.5 \pm 12.1)}$ had adhered to the Matrigel, $\mathrm{p}<0.01$ compared to PC-3 $3^{\mathrm{WT}}(46.0 \pm 10.9)$ and $\mathrm{PC}-3^{\mathrm{pEF}}$ (32.67 \pm 6.71$)$ controls (Fig. 2A). In contrast, a reduction in the number of adhered cells was seen in PC-3 ${ }^{\text {GDF-9rib3 }}(20.85 \pm 2.03)$ cells, $\mathrm{p}<0.01$ compared to both PC-3 ${ }^{\mathrm{WT}}(46.02 \pm 7.84)$ and

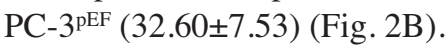

In order to further examine the effect of GDF-9 on prostate cancer cells, recombinant GDF-9 (rh-GDF-9) was generated using 3 T3 cells with overexpressed GDF-9 (3T3 $3^{\text {GDF-9N4exp.) }}$ (Fig. 1C). After 40-min exposure to $20 \mathrm{ng} / \mathrm{ml}$ of rh-GDF-9, the cells were stained with crystal violet and counted. These treated cells demonstrated a significantly increased adhesiveness $(50.07 \pm 4.89)$ in comparison to the untreated cells (37.33 \pm 2.09$), p=0.05$ (Fig. 2C).
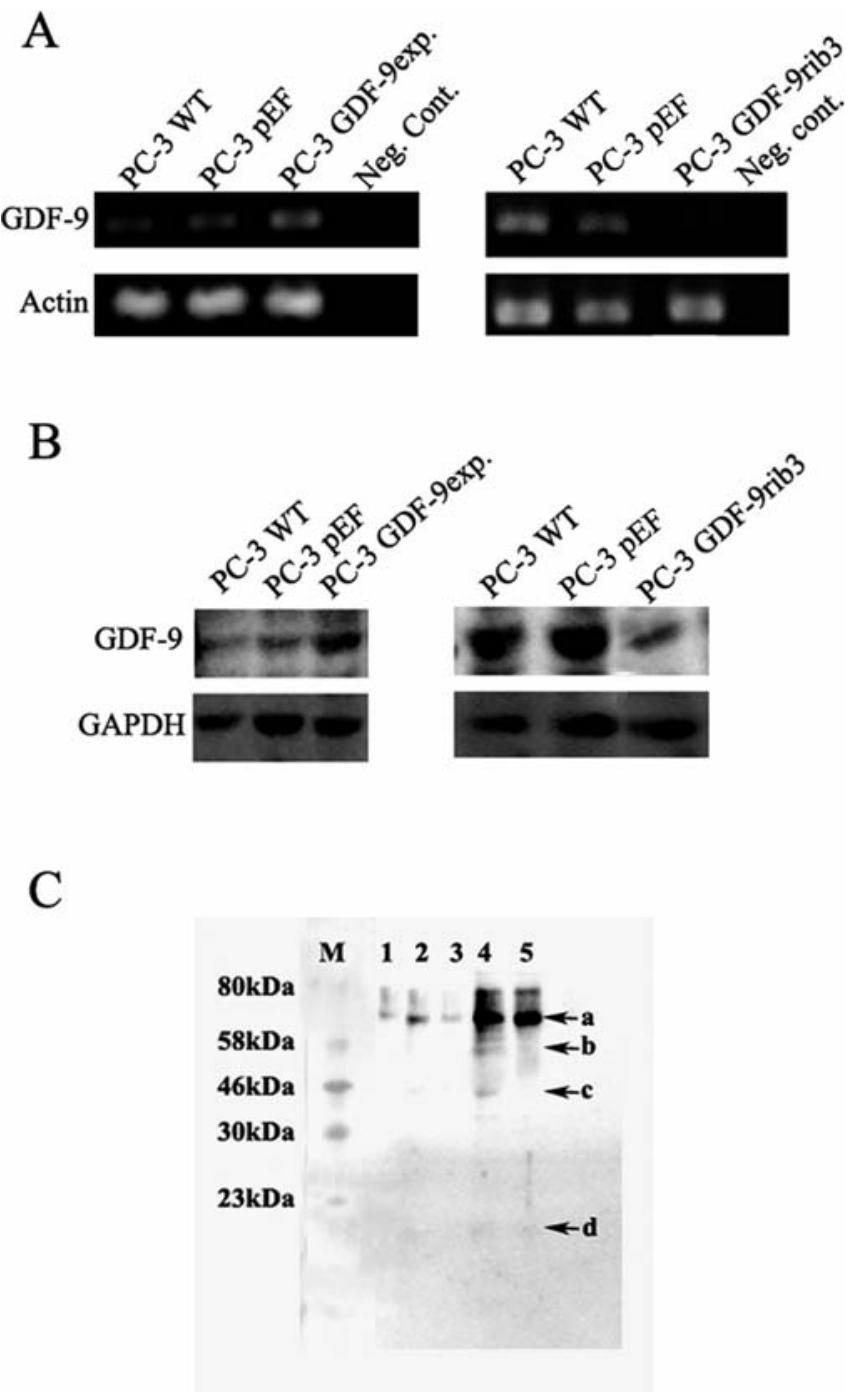

Figure 1. Verification of GDF-9 overexpression and knock-down in PC-3 cells. (A) mRNA level using PCR and (B) protein level using Western blot analysis. (C) Western blot analysis verifying purification of rh-GDF-9 from 3T3 transfectants after desaltification; a, is the GDF-9 proprotein (70 $\mathrm{kDa}), \mathrm{b}$, the precursor protein $(57 \mathrm{kDa}), \mathrm{c}$, the mature ligand dimer (40 $\mathrm{kDa})$; and $\mathrm{d}$, the mature monomer $(18 \mathrm{kDa})$. $\mathrm{M}$ refers to the molecular

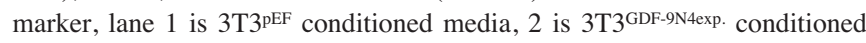
media, 3 is $1 \mu \mathrm{m}$ imidazole (elution buffer used for recombinant protein purification), 4 is rh-GDF-9 elution 1 and 5 is rh-GDF-9 elution 2.

Influence on motility of prostate cancer cells by GDF-9. The cells were additionally evaluated for their motility using a cytodex-2 bead motility assay. GDF-9 overexpression demonstrated enhanced cell motility compared to the controls. A significantly larger proportion of PC-3 $3^{\text {GDF-9exp. cells }(99.2 \pm 16.1)}$ had migrated from the beads onto the surface of the culture plate in comparison with the PC-3 ${ }^{\mathrm{WT}}(64.1 \pm 10.0)$ and $\mathrm{PC}-3^{\mathrm{pEF}}$ $(76.56 \pm 2.22)$ controls, $\mathrm{p}=0.049$ vs. PC $-3^{\mathrm{WT}}$ and 0.073 vs. PC-3 ${ }^{\mathrm{pEF}}$ (Fig. 3A). In contrast, the GDF-9 knock-down cells demonstrated reduced cell motility compared to these controls. The number of migrating cells in PC-3 ${ }^{\text {GDF-9rib3 }}$ was $(29.67 \pm 2.00), \mathrm{p}<0.05$ and $\mathrm{p}<0.01$ compared to $\mathrm{PC}-3^{\mathrm{WT}}$ and PC-3 ${ }^{\mathrm{pEF}}$, respectively (Fig. 3B).

GDF-9 up-regulates expression of FAK and paxillin. With the intention of determining a mechanism by which GDF-9 can 
A
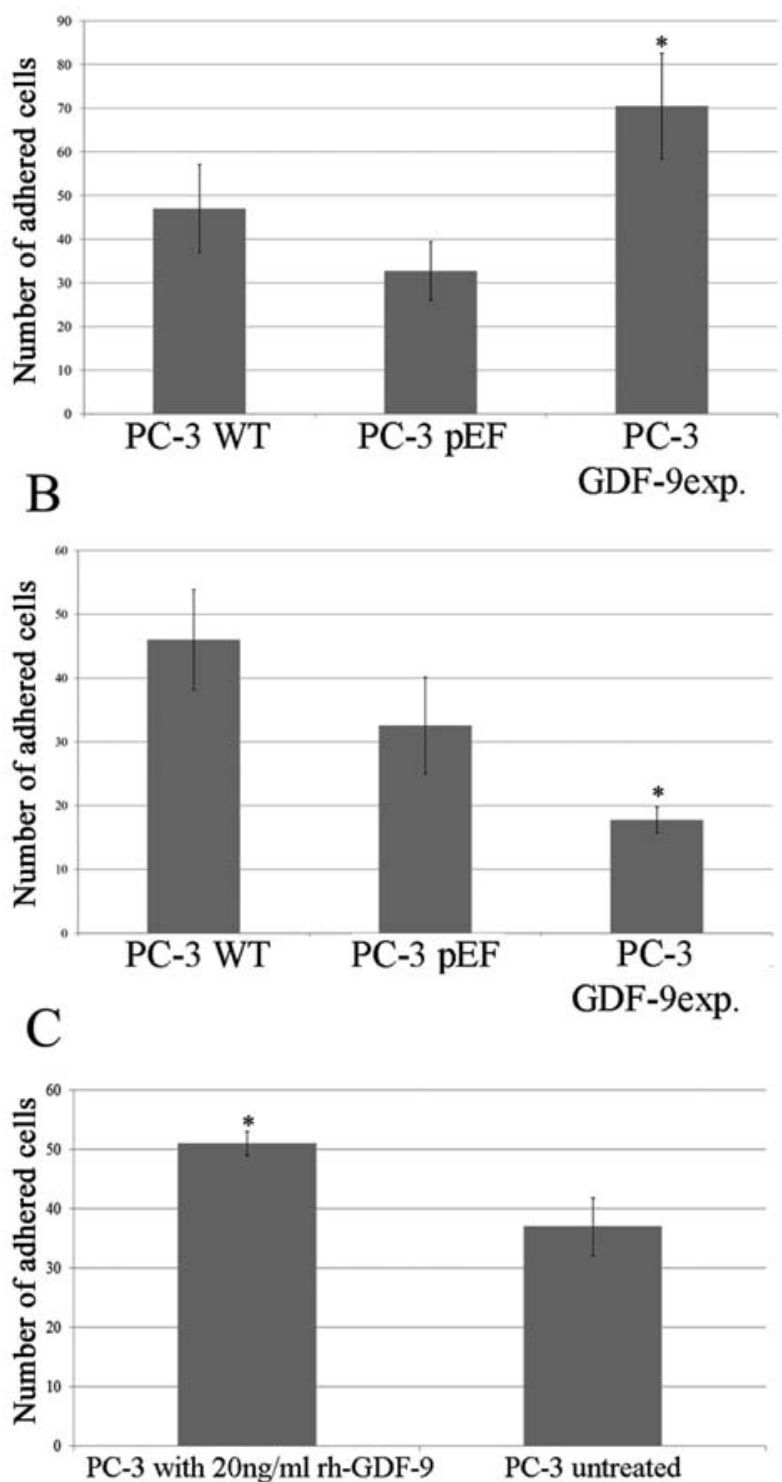

Figure 2. Effect of GDF-9 on in vitro cell adhesion of PC-3 cells. (A) The adhesive capacity of PC-3GDF-9exp. cells was significantly increased in comparison to controls. (B) Knocking-down GDF-9 inhibited PC-3 adhesive capacity. (C) The adhesive capacity of PC-3 cells was increased when treated with rh-GDF-9, compared to the non-treated cells. Data shown are representative of at least 3 independent repeats. ${ }^{*} \mathrm{p}<0.01$ compared to both controls $(n=6)$.

promote prostate cancer cell adhesion and motility, the expression levels of well-established adhesion molecules FAK and paxillin were analysed at both the mRNA and

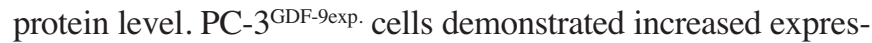
sion of both FAK and paxillin compared to both controls (Fig. 4A and B). In addition, PC-3 $3^{\text {GDF-9rib3 }}$ cells had similar mRNA levels of both molecules to the controls.

To further confirm this hypothesis, PC-3 WT cells were treated with rh-GDF-9 for varying amounts of time to see if exogenous GDF-9 would have a similar effect on FAK and paxillin expression. Using PCR and Western blot analysis, expression levels of FAK and paxillin were analysed. Levels of FAK and paxillin mRNA were increased after only half an
A

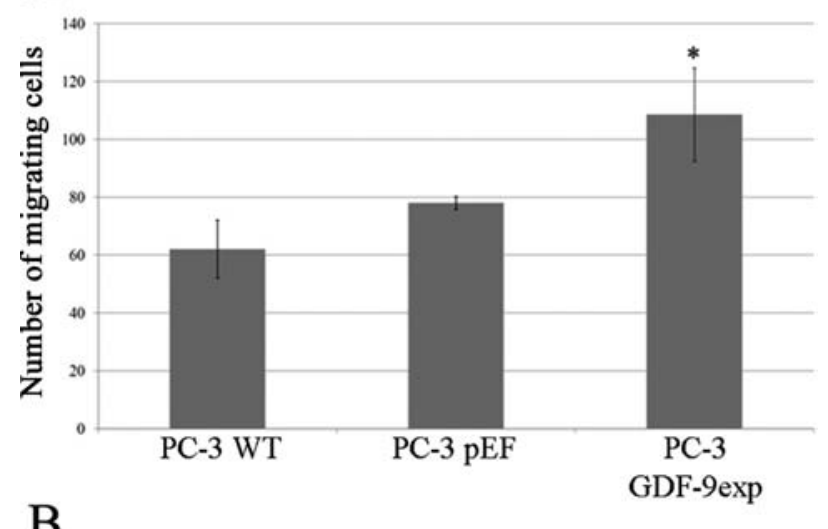

B

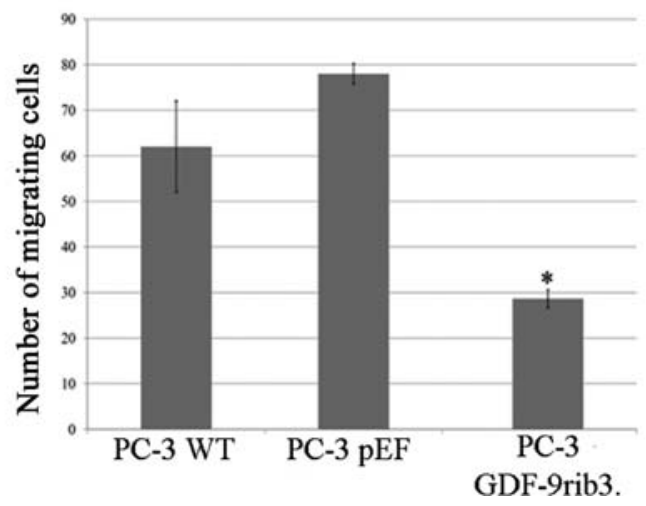

Figure 3. Effect of GDF-9 on in vitro cell motility of PC-3 cells. (A) The

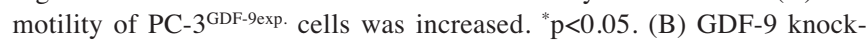
down cells showed reduced motility. ${ }^{*} \mathrm{p}<0.01$. Data shown are representative of at least 3 independent repeats $(n=6)$.

hour of treatment with rh-GDF-9 (Fig. 4C). In the case of protein levels however, expression of paxillin was only increased after $4 \mathrm{~h}$ treatment and that of FAK only after $24 \mathrm{~h}$ (Fig. 4D). Furthermore, protein levels of phosphorylated and hence activated FAK and paxillin (p-FAK and p-paxillin), were analysed in order to determine if GDF-9 not only upregulates but also activates these molecules. Indeed, levels of p-FAK and p-paxillin were up-regulated at similar timepoints as their non-phosphorylated counterparts compared to the untreated controls, suggesting that GDF-9 not only upregulates expression of FAK and paxillin but also activates them.

GDF-9 signals via Smad dependent pathway using Smad3. BMPs can signal via two different pathways, Smad-dependent or Smad-independent. Previous literature suggests that GDF-9 signals through ALK-5 and BMPR-II via Smads 2 and 3 in the oocyte (10). In order to determine if the same is true in prostate cancer cells, the effect of GDF-9 on the serine/ threonine phosphorylation of Smad3 was investigated. Levels of pSmad3 were first examined in the GDF-9 overexpressing cells using immuno-fluorescent staining (Fig 5B). PC-3 GDF-9exp. cells demonstrated significantly stronger nuclear staining of pSmad3 compared to controls. To further confirm the involvement of Smad3 in GDF-9 signalling in prostate cancer cells, PC-3 cells were treated with $20 \mathrm{ng} / \mathrm{ml}$ rh-GDF-9 for different periods of time, after which protein levels of pSmad3 and 

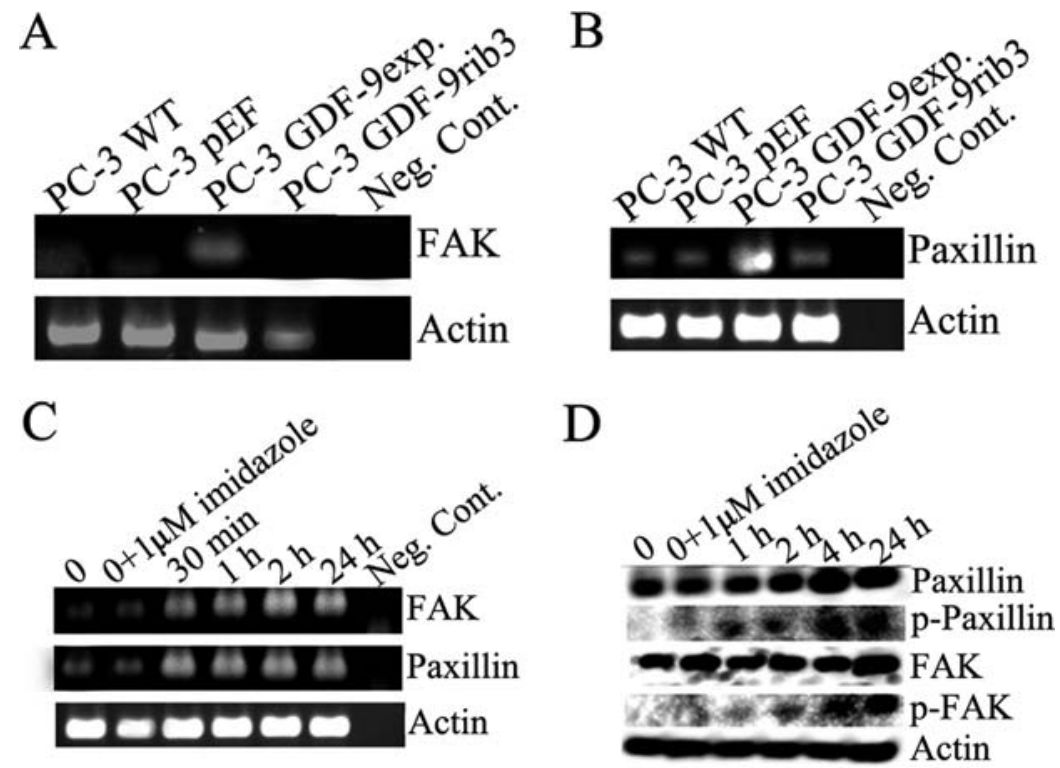

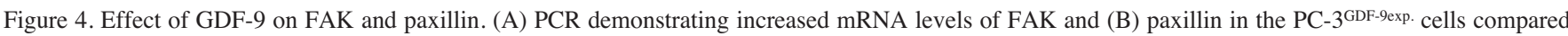
to controls and knock-down cells. (C) PC-3 cells treated with $20 \mathrm{ng} / \mathrm{ml}$ rh-GDF-9 had increased expression of FAK and paxillin at the mRNA level with PCR, and (D) protein level using Western blot analysis, compared to controls. In addition, activated forms of both FAK and paxillin (p-FAK and p-paxillin) were increased when treated with rh-GDF-9. Imidazole $(1 \mu \mathrm{M})$ was used as a control as it was used as the elution buffer during metal affinity chromatography and purification of rh-GDF-9

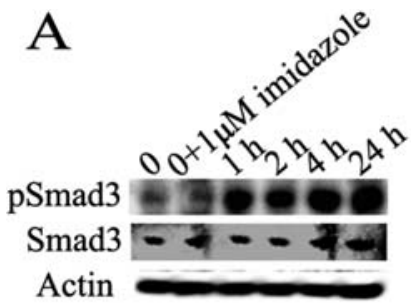

$\mathrm{C}$

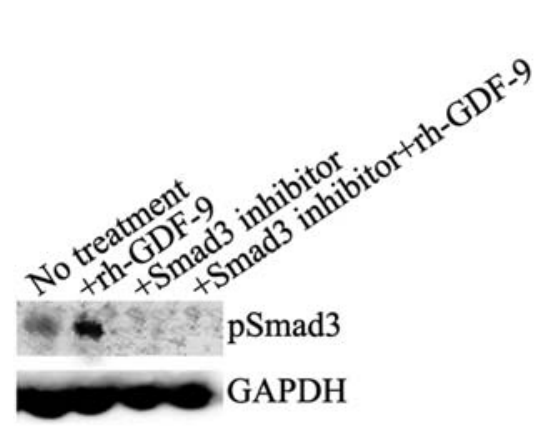

B

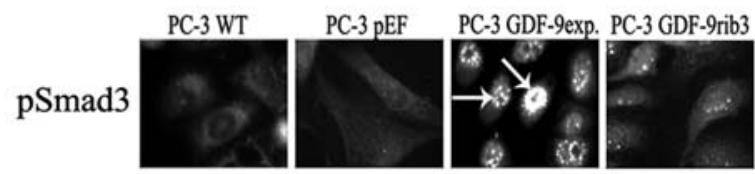

$\mathrm{D}$

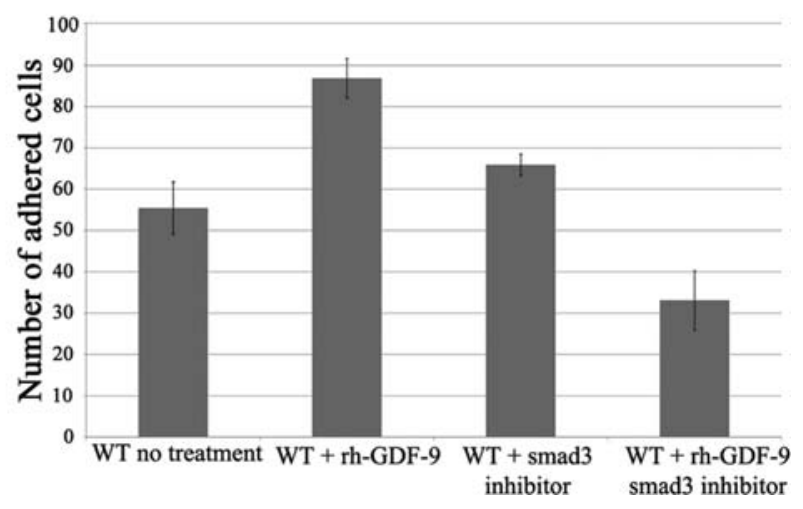

Figure 5. GDF-9 signalling via Smad3. (A) PC-3 cells treated with rh-GDF-9 demonstrated increased pSmad3 protein levels compared to control. Levels of

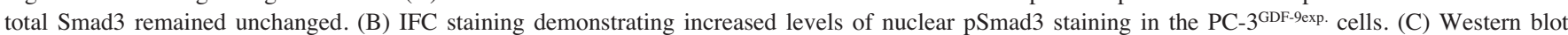
analysis showing PC-3 cells treated with Smad3 inhibitor resulting in reduced expression of pSmad3. (D) Treating cells with Smad3 inhibitor resulted in inhibition of GDF-9 associated promoted adhesion.

total Smad3 were analysed by Western blot analysis (Fig. 5A). Expression of pSmad3 protein was up-regulated by rh-GDF-9 after only $1 \mathrm{~h}$ of treatment while levels of non-phosphorylated Smad3 remained unchanged.
The Smad3 inhibitor prevents phosphorylation and hence activation of Smad3, and when treating PC-3 WT cells with this inhibitor, the up-regulation in $\mathrm{pSmad} 3$ expression seen with rh-GDF-9 treatment was inhibited (Fig. 5C). 

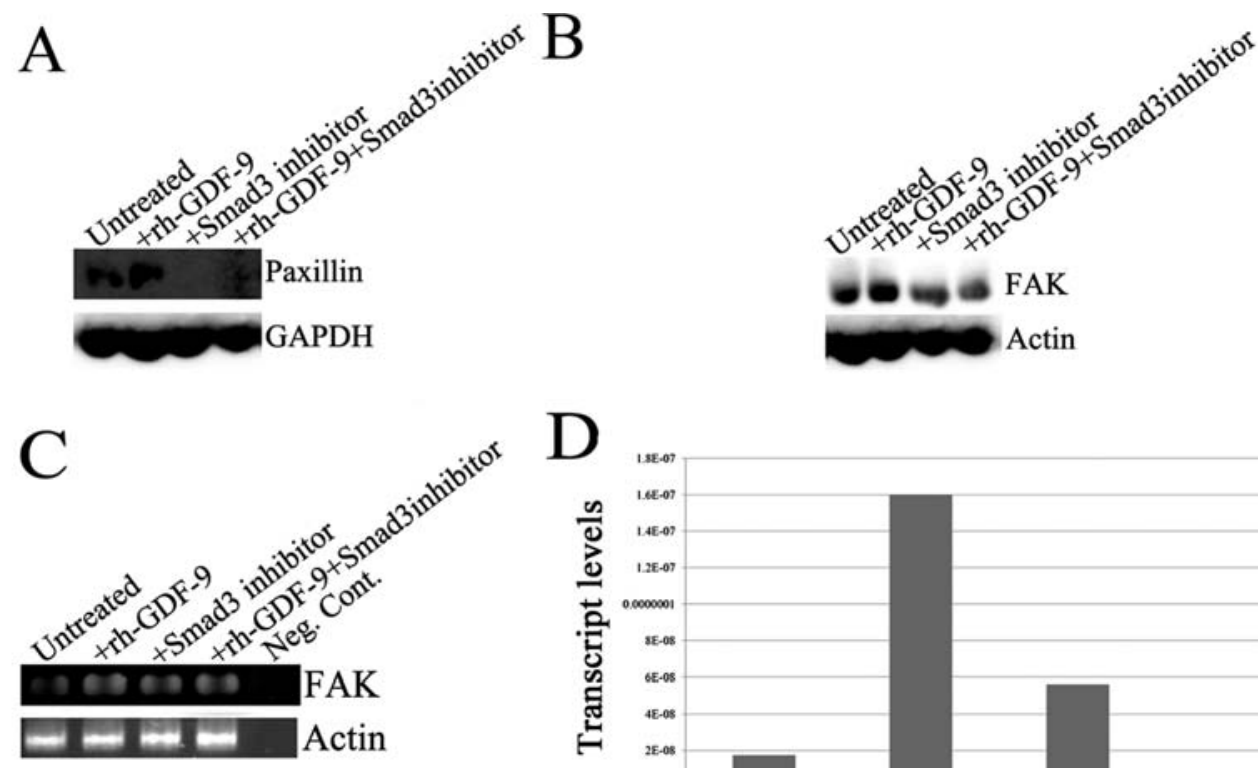

$\mathrm{D}$
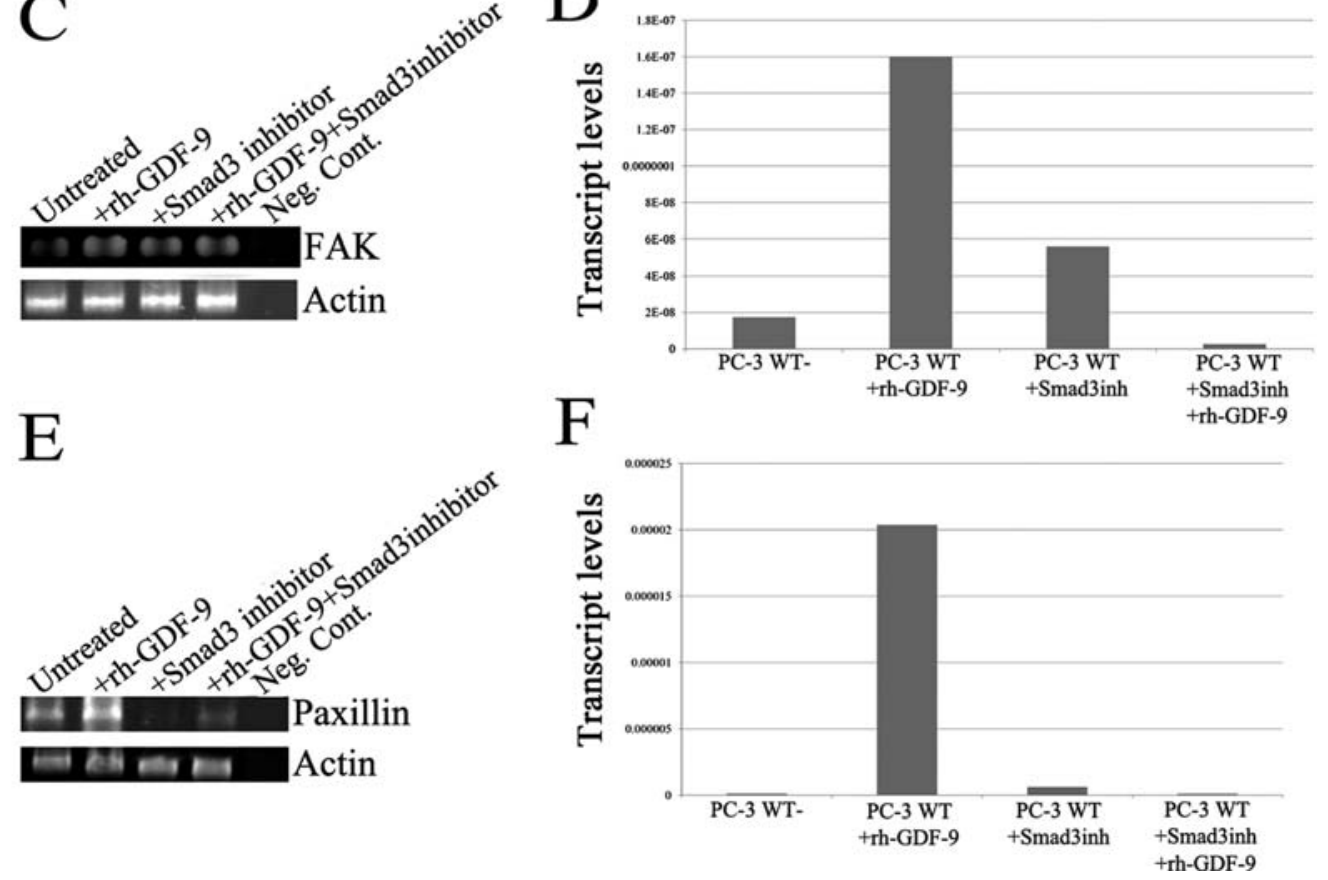

Figure 6. GDF-9 signalling via Smad3 regulates FAK and paxillin. PC-3 cells were treated with serum-free media, $20 \mathrm{ng} / \mathrm{ml} \mathrm{rh}-\mathrm{GDF}-9,3 \mathrm{ng} / \mathrm{ml} \mathrm{Smad} 3$ inhibitor or both rh-GDF-9 and Smad3 inhibitor, respectively. Western blot analysis showing (A) FAK and (B) paxillin protein levels in treated PC-3 cells. The up-regulation in levels of FAK and paxillin associated with rh-GDF-9 was inhibited when cells were treated with Smad3 inhibitor. (C) FAK mRNA levels were analysed using both normal and (D) Q-PCR. (E) Paxillin mRNA levels using normal and (F) Q-PCR.

Additionally, when these cells were exposed to Smad3 inhibitor along with rh-GDF-9 (33.1 \pm 7.18), the previously seen GDF-9 associated increase in cellular adhesion $(86.9 \pm 4.76)$ was inhibited, suggesting that GDF-9 signals via Smad 3 to exert its effects on prostate cancer cell adhesion, $\mathrm{p}=0.002$ compared to PC- 3 treated with rh-GDF- 9 and $\mathrm{p}=0.027$ vs. untreated control (Fig. 5D).

GDF-9 up-regulates FAK and paxillin by signalling via Smad3. In order to establish whether GDF-9 up-regulation of FAK and paxillin is due to Smad3 signalling, PC-3 cells were treated with $20 \mathrm{ng} / \mathrm{ml} \mathrm{rh}-\mathrm{GDF}-9,3 \mathrm{ng} / \mathrm{ml} \mathrm{Smad} 3$ inhibitor, and both rh-GDF-9 and Smad3 inhibitor, respectively. FAK and paxillin mRNA levels were analysed using both conventional and Q-PCR, and protein levels were analysed with Western blotting. When the PC-3 cells were treated with rhGDF-9 alone, expression of FAK and paxillin was increased. However, the up-regulation of both FAK and paxillin mRNA and protein levels was inhibited when PC-3 cells were treated with a Smad3 inhibitor. These levels were similar to those seen in the untreated control. In addition, when these cells were treated with both a Smad3 inhibitor and rh-GDF-9, FAK and paxillin levels remained low, suggesting that GDF-9 signals via Smad3 to up-regulate expression of these adhesion molecules (Fig. 6).

\section{Discussion}

GDF-9 is a follicular growth factor vital during the early stages of follicular development (11). Its role in cancer however is unclear. We have previously shown that GDF-9 can inhibit breast cancer cell invasiveness and that its expression correlates with good prognosis (12). Conversely, a different group demonstrated up-regulation of GDF-9 expression in more aggressive oral squamous carcinoma cell lines, while another reported GDF-9 up-regulation in lung adenocarcinoma cell lines with silenced mutant P53, suggesting that GDF-9 may aid in progression of these cancers $(13,14)$.

This current study is the first to investigate the role of GDF-9 on the biological properties of prostate cancer cells. Our results show that by overexpressing endogenous GDF-9 in PC-3 cells, cell motility and adhesion was increased. Treating PC-3 WT cells with rh-GDF-9 further showed that exogenous GDF-9 can also promote the adhesive capacity of 
these cells. In addition, knocking-down GDF-9 in the same cells resulted in the opposite and reduced effect of both properties. These results suggest that GDF-9 plays an important role in regulating prostate cancer cell adhesion and motility.

Furthermore, PC-3GDF-9exp. cells, and PC-3 WT cells treated with rh-GDF-9, demonstrated with increased levels of FAK and paxillin expression, focal adhesion-associated proteins that transmit signals downstream of integrins. These downstream integrin signals are important in regulating cellular properties including cell adhesion, migration, motility and survival (15). Cell motility is a process involving changes in actin filament dynamics and cell adhesion sites that lead to the formation of membrane protrusions and traction forces (15). FAK has been shown to influence the cytoskeleton, cell adhesion structure sites, and membrane protrusions to regulate cell movement (16). Paxillin meanwhile interacts with FAK to recruit signal cascade molecules into close proximity in order to allow for efficient signal transduction (17).

In addition to the up-regulation of FAK and paxillin, GDF-9 also appeared to increase their phosphorylation and activation. Phosphorylation of these molecules normally occurs in response to integrin mediated cell adhesion and growth factor stimulation (17). This suggests that GDF-9 may act as a growth factor to stimulate up-regulation and activation of FAK and paxillin, resulting in increased prostate cancer cell adhesion and motility. Another BMP that has been reported to have an effect on these molecules is BMP-7. Primary cultures of chondrocytes treated with rhBMP-7, demonstrated an up-regulation of FAK and paxillin expression (18). In PC-3 prostate cancer cells however, with knocked out BMP-7 demonstrated enhanced immunofluorescent staining of paxillin and FAK, and a promotion in cell matrix adhesion, invasion and motility (19).

BMPs can signal via two different pathways; the Smaddependent and Smad-independent (4). For example, BMP-9 was recently shown to signal via Smad1 to inhibit PC-3 cell growth, adhesion, invasion and migration (7). BMP-10 meanwhile was shown to have a similar effect on PC-3 cells, but via the Smad-independent pathway (20). In the case of GDF-9, we now show Smad dependent signalling via Smad3. PC-3 cells treated with rh-GDF-9 demonstrated increased protein levels and enhanced immuno-fluorescent nuclear staining of pSmad3. In addition, when PC-3 cells were treated with Smad3 inhibitor, the increased adhesive capacity and up-regulation of FAK and paxillin seen by rh-GDF-9 treatment was inhibited, suggesting that GDF-9 may signal via Smad3 to up-regulate both FAK and paxillin in order to promote their adhesiveness.

In conclusion, this study shows that both endogenous and exogenous GDF-9 can promote the adhesive and motile capacity of PC-3 prostate cancer cells, through Smad-3dependent up-regulation and activation of focal adhesion molecules, FAK and paxillin. These results imply that GDF-9 may act as a survival factor in prostate cancer, promoting disease progression.

\section{Acknowledgements}

The authors wish to thank the Dezna Robins Jones Charitable Foundation and Cancer Research Wales for supporting this study.

\section{References}

1. Jemal A, Siegel R, Ward E, Hao Y, Xu J and Thun MJ: Cancer statistics, 2009. CA Cancer J Clin 59: 225-249, 2009.

2. Ye L, Lewis-Russell JM, Kyanaston HG and Jiang WG: Bone morphogenetic proteins and their receptor signaling in prostate cancer. Histol Histopathol 22: 1129-1147, 2007.

3. Chen D, Zhao M and Mundy GR: Bone morphogenetic proteins. Growth Factors 22: 233-241, 2004.

4. Shi Y and Massague J: Mechanisms of TGF-beta signaling from cell membrane to the nucleus. Cell 113: 685-700, 2003.

5. Nohe A, Hassel S, Ehrlich M, et al: The mode of bone morphogenetic protein (BMP) receptor oligomerization determines different BMP-2 signaling pathways. J Biol Chem 277: 5330-5338, 2002.

6. Bobinac D, Maric I, Zoricic S, et al: Expression of bone morphogenetic proteins in human metastatic prostate and breast cancer. Croat Med J 46: 389-396, 2005.

7. Ye L, Kynaston $\mathrm{H}$ and Jiang WG: Bone morphogenetic protein-9 induces apoptosis in prostate cancer cells, the role of prostate apoptosis response-4. Mol Cancer Res 6: 1594-1606, 2008.

8. Aaltonen J, Laitinen MP, Vuojolainen K, et al: Human growth differentiation factor 9 (GDF-9) and its novel homolog GDF-9B are expressed in oocytes during early folliculogenesis. J Clin Endocrinol Metab 84: 2744-2750, 1999.

9. Jiang WG, Hiscox S, Hallett MB, Scott C, Horrobin DF and Puntis MC: Inhibition of hepatocyte growth factor-induced motility and in vitro invasion of human colon cancer cells by gamma-linolenic acid. Br J Cancer 71: 744-752, 1995.

10. Mazerbourg S, Klein C, Roh J, et al: Growth differentiation factor-9 signaling is mediated by the type I receptor, activin receptor-like kinase 5. Mol Endocrinol 18: 653-665, 2004.

11. Laitinen M, Vuojolainen K, Jaatinen R, et al: A novel growth differentiation factor-9 (GDF-9) related factor is co-expressed with GDF-9 in mouse oocytes during folliculogenesis. Mech Dev 78: 135-140, 1998.

12. Hanavadi S, Martin TA, Watkins G, Mansel RE and Jiang WG: The role of growth differentiation factor-9 (GDF-9) and its analog, GDF-9b/BMP-15, in human breast cancer. Ann Surg Oncol 14: 2159-2166, 2007.

13. Ma LL, Sun WJ, Wang Z, Zh GY, Li P and Fu SB: Effects of silencing of mutant p53 gene in human lung adenocarcinoma cell line Anip973. J Exp Clin Cancer Res 25: 585-592, 2006.

14. Zhuang Z, Jian P, Longjiang L, Bo $\mathrm{H}$ and Wenlin X: Oral cancer cells with different potential of lymphatic metastasis displayed distinct biologic behaviors and gene expression profiles. J Oral Pathol Med 39: 168-175, 2010.

15. Brakebusch $\mathrm{C}$ and Fassler R: The integrin-actin connection, an eternal love affair. EMBO J 22: 2324-2333, 2003.

16. Mitra SK, Hanson DA and Schlaepfer DD: Focal adhesion kinase: in command and control of cell motility. Nat Rev Mol Cell Biol 6: 56-68, 2005.

17. Turner CE: Paxillin. Int J Biochem Cell Biol 30: 955-959, 1998.

18. Vinall RL, Lo SH and Reddi AH: Regulation of articular chondrocyte phenotype by bone morphogenetic protein 7 , interleukin 1, and cellular context is dependent on the cytoskeleton. Exp Cell Res 272: 32-44, 2002.

19. Ye L, Lewis-Russell JM, Kynaston H and Jiang WG: Endogenous bone morphogenetic protein-7 controls the motility of prostate cancer cells through regulation of bone morphogenetic protein antagonists. J Urol 178: 1086-1091, 2007.

20. Ye L, Kynaston H and Jiang WG: Bone morphogenetic protein-10 suppresses the growth and aggressiveness of prostate cancer cells through a Smad-independent pathway. J Urol 181: 2749-2759, 2009. 